\title{
How can mentoring support women in a male-dominated workplace? A case study of the UK police force
}

Jenni Jones ${ }^{1}$

\begin{abstract}
There is little academic research in relation to mentoring, learning and women, particularly in the male-dominated organizational context of the UK Police force. Currently, there is a Home Office drive to address inequality within the UK Police with a number of initiatives proposed including mentoring interventions, flexible working arrangements and positive-action recruitment initiatives. The purpose of this study is to investigate what policewomen mentees and mentors perceive they are learning through formal mentoring over time and how this makes a difference for them in the workplace. This will provide insights into whether Government investment in formal mentoring is the right intervention to help create a more gender-reflective, more equal workforce, in the Police. This study takes a critical realist position and an interpretivist theoretical perspective investigating a single case study organization. Key themes, spread across the four phases of the mentoring lifecycle were explored through 68 semi-structured interviews and four focus groups. Key findings are uncovered in relation to learning outcomes for these policewomen, both as mentees and mentors. It was found that mentoring added value across all four learning domains (cognitive, skills, affectiverelated and social networks) and that the largest number of responses over time, were in relation to the affective-related domain, particularly building self-confidence. These findings are significant as they demonstrate that formal mentoring programmes can support and empower women within the specific workplace of the UK Police. In conclusion, if women are being precluded from breaking the "glass labyrinth" because of lack of knowledge, opportunity and networks to progress within this context, then mentoring could be part of this solution. If the masculine organizational culture is also creating prejudice and obstacles for women in the workplace (the "concrete floor"), then mentoring might be one way towards breaking down these barriers. In addition, if all (or some) of these factors are contributing to women's lower self-confidence levels and the "sticky floor" syndrome, then again the findings suggest that mentoring may be part of the solution towards empowering women beyond their current role. It is hoped that these insights will impact the emphasis put on the various Home Office recommendations and the initiatives offered by different Police forces. It is also hoped that these insights will have implications for other organizations that are considering investing in mentoring interventions, for similar groups or beyond. This article is published as part of a collection on the role of women in management and the workplace.
\end{abstract}

\footnotetext{
${ }^{1}$ University of Wolverhampton, Wolverhampton, UK Correspondence: (e-mail: jenni.jones@wlv.ac.uk)
} 


\section{Introduction}

- his research is set within the context of the UK Police force. This is an intriguing area to research as the organisation is still considered to have a "cult of masculinity" (Waddington, 2006) with a well-documented history of gender inequality: currently $29 \%$ of all police officers are women, with $23 \%$ in senior ranks (Allen and Dempsey, 2016). There have long been suggestions of racial prejudice and marginalization towards women in the Police (Westmarland, 2001). Heidensohn (1995) argued:

Being a distinguishable minority creates the potential for conflict or constraint in any situation; being a part of a small minority in such a cohesive group as the police is a further problem, but to be a woman in such an insistently masculinist culture triples the problems (p. 129).

Although this quote is over 20 years old, there is still considered to be horizontal and vertical gender segregation (Gianettoni and Guilley, 2016) within the UK Police force. The Home Office Assessment of Women in the Police Service (2010), the British Association for Women in Policing Gender Agenda (2014) report and the Home Affairs Committee Police Diversity report (2016), all suggest that more can be done and that mentoring may be one way to address this inequality.

There are existing knowledge gaps in relation to formal mentoring and learning, women and the UK Police force. Articles have been written about mentoring within the Police elsewhere (Aremu and Adeyoju, 2003; Arter, 2006; Tyler and McKenzie, 2011; Chaney, 2015), but very few articles have been written about mentoring in the UK Police (Carson, 2009; Flynn, 2010; Hamlin and Sage, 2011). Although articles have been written about learning and mentoring (Jones, 2012; St-Jean and Audet, 2012; Garvey, 2014), and women within mentoring programmes (Noe, 1988; Ragins, 1996; Clutterbuck and Ragins, 2002), none have been written in relation to learning within a specific women's only mentoring programme in the UK Police force.

As mentoring is becoming increasingly popular as a learning and development intervention, (Allen et al., 2006; CIPD surveys 2005 to 2015) and women in the Police are becoming a popular area of focus (Barrett, 2015; ITV Report, 2015), it is important to be able to demonstrate the practical and real contribution that mentoring can make towards women in the workplace.

Therefore, the purpose of this research is to investigate the value of formal mentoring and specifically how mentoring can support women within the UK Police context. To investigate this, the key overarching strategic questions that guided the study were:

- What do policewomen mentees and mentors perceive they are learning during their formal mentoring relationships?

- How do the comments on learning change over time for both parties?

- What difference do they perceive their learning, from mentoring, makes within the workplace?

The literature review that follows will discuss what is already known about mentoring and learning, women in the workplace and the UK Police. The methodology section will discuss the longitudinal case study research approach taken (Yin, 2014) and the semi-structured interview and focus group methods used over time. Content analysis (Flick, 2009; Easterby-Smith et al., 2012) was used to disentangle the information gathered and responses were coded against an established learning domain framework (Wanberg et al., 2003; Hezlett, 2005). The findings section demonstrates the key domains in which the mentees and mentors have learnt, and the "slow burn" and/or intensity of their learning over time. This leads to the discussion and conclusion sections that imply that this formal mentoring programme has helped to increase personal learning for both women mentees and mentors, beyond the expected cognitive and skills levels towards more deeper affective-related learning, which has made a difference for them back into the workplace.

\section{Literature review}

Mentoring and learning. In order to avoid a lengthy debate about mentoring definitions, but recognizing that there are variables between the United States, the United Kingdom, European and Australian commentators, for the purpose of simplicity, mentoring for this research is:

... a unique interpersonal relationship between two individuals (Janasz et al. 2013: 1437).

The key purpose of mentoring relationships are to support and challenge both parties towards their learning and development (Parsloe and Wray, 2004; Garvey, 2014). Parsloe and Wray suggest that when all the theory is taken away, mentoring is still a simple one-to-one meeting held regularly to support the mentee in their ambitions to make improvements either in their personal or working life.

The intention of the women's only mentoring programme, investigated in this study, was to encourage the movement of women into higher levels in the organization. The Police mentors agreed definition for their formal mentoring programme was;

Mentoring is a supportive, confidential relationship, enabling one to realize and achieve their potential.

Academics still consider formal mentoring to be underresearched (Wanberg et al., 2003; Eby and Lockwood, 2005; Allen et al., 2006; Baugh and Fagenson-Eland, 2007; Parise and Forret, 2008; Baranik et al., 2010; Chun et al., 2012). The world of practice seems to recognize its benefits but the concern is that its rapid rise in the world of business has resulted in a lack of clarity about what formal mentoring actually does and what is learnt by those involved. In short, it is still not fully understood what value formal mentoring adds (Ragins and Kram, 2007; Chun et al., 2012). This article attempts to provide evidence on whether formal mentoring can make a positive difference in the workplace.

It is known that mentoring creates benefits for the mentee and the organization in relation to performance, motivation, knowledge, skills and change but less so for the mentor (Megginson et al. 2006) and that learning outcomes can be extrinsic and intrinsic (Jones, 2012; St-Jean and Audet, 2012). However, it is not sufficiently understood in the world of practice how both parties benefit. Studies tend to show the benefits to either mentees (Phinney et al., 2011) or mentors but rarely investigate the benefit for both parties together (Philip and Hendry, 2000; Laiho and Brandt, 2012; Garvey, 2014; Snoeren et al., 2016). This study will investigate the learning for both parties.

Mentoring activity has gained much momentum in private and public sector businesses, in small and large business enterprises, and within educational institutions and social contexts (Garvey, 2014). This high degree of interest is due to mentoring developing a reputation as a vehicle to develop human resources in an organization, creating learning and positive outcomes for both the individuals involved and the organization (Hansford et al., 2002; Gibson, 2004; Allen et al., 2006; Egan and Song, 2008; Garvey, 2014; Wang et al., 2014). Thurston et al. (2012) suggest this is because mentoring is an opportunity for individuals to learn, to realize their potential, to make improvements and to 
ultimately make changes for the better. This resonates well with the academic and agreed definitions mentioned above.

Women in the workplace. Workplaces are becoming more diverse for a number of reasons; women's participation rates have increased over the last 40 years as they no longer leave the workplace once they get married, they are much more likely to return to work and continue to work after having children and there is a growth of ethnic minority populations joining the working population too (Konrad, 2006). This is because of changes in legislation, for instance the Equality Act 2010, forcing workplaces to be more reasonable about how they recruit and retain employees, that is, allowing more flexible working patterns (part-time, job share, working from home) for returning mothers, workplace positive action programmes etc. In short, changes in the demographics, greater international competition and potential skills shortages in the United Kingdom have forced businesses to recognize and support the development of the increasing number of economically active women and minority groups within the workforce (Perrons, 2003; ONS, 2015).

Even though, there are an increasing number of women in the workplace and research shows that women and men are equal in ambition, ability and commitment in the workplace (Hyde, 2014), there is still horizontal and vertical segregation of the labour market (Gianettoni and Guilley, 2016). Horizontally in respect of gendered occupations occupied by mainly men (for instance, the UK Police force) and vertically where often men are in more senior positions (for instance, the UK Police force.) This leads to women being within jobs that are more stereotypically female (Derks and Ellemers, 2016) being paid less and having lower status than men. Now, in the United Kingdom, $8 \%$ of women are Managers/Directors and Senior Officials (ONS, 2015), but this rises to 30\% if Professional occupations are added. This shows that, although rising, there is still sexual division of professional orientation (Vouillot, 2007) whereby men are over-represented in the higher levels and women tend to be over-represented in highly feminized occupations lower paid jobs:

The general pattern is that women have increased their share of professional and managerial occupations, albeit at lower levels, at the same time as increasing their share of low-paid, low skill jobs. The consequence is that women as a group have become polarized, as small numbers have gained access to higher echelons of occupational hierarchies, the vast majority remains concentrated at the lower end (Kirton and Greene, 2010: 15).

Diversity and mentoring have been the focus of considerable research attention (Wanberg et al., 2003; Devos, 2007; Chandler and Ellis, 2011) and an often-touted outcome is the assistance that mentoring might provide in helping women and minority groups to gain access to personal networks needed to navigate often complex social and organizational environments (Wanberg et al., 2003; Gibson, 2004). Therefore, empirical evidence suggests mentoring is becoming especially relevant to issues of diversity, revealing the importance of mentoring support whilst women still contend with the "glass labyrinth" (Eagly and Carli, 2007; Hoyt, 2010), which involves finding ways through the "concrete wall" (Eagly and Carli, 2007), the "glass ceiling" (Richards, 2001; Gibson, 2004; Kirton and Greene, 2010), and the "glass cliff" linked to organizational prejudice towards women typically created by and within the organizations, and the "sticky floor" (Shambaugh, 2007) typically created by women themselves.

The UK police. The new Police in the United Kingdom was established by the State in 1829 to ensure social control and public order on the streets. A "cult of masculinity" (Waddington, 2006) was established by the strong men who were sent out to deal with difficulties on the street. Policing was seen as "a man's world" (Barrett, 2015), which ensured that men were given the more powerful positions and monitored/controlled the flow of talent through the hierarchy; even now within the Police it can still be seen that there are typically more men within the more active physical/Firearm type roles and more women within more office-based domestic/childcare type roles. In the last few decades, the purpose of the Police role has developed beyond the streets and into the private lives of citizens whereby the Police are dealing more with social, family/domestic issues. This has changed the priorities of policing towards a more socially responsible, community focused role. This in turn has created a shift in the structure of the organization in relation to the composition of the jobs available towards more supportive, victimsupport type roles. In theory, this should have opened up more opportunities for women, and as a result created a more gender reflective, more equal workforce. Statistics show that an equal workforce in the Police has not been established yet; there are still only $23 \%$ of women in senior positions (Allen and Dempsey, 2016), but attempts have been made through certain targeted learning and development activities to work towards this through mentoring programmes, high potential leadership development programmes and Springboard courses aimed at minority groups.

Despite this, women are still considered to be marginalized in the Police.

Westmarland (2001) questions whether the issue is with the organizational "cop culture" (Reiner, 2012) and more specifically the management prejudices within it;

as a traditional, patriarchal, quasi-military group of men, hostile to women, which strives to perpetuate clearly drawn lines dividing masculine and feminine (p. 23).

This suggests that those part of the majority group (men) have better opportunities to network and build supporting relationships in the workplace than those that don't. The assumption made is that women have access to less senior workplace networks than men. This in turn suggests that women would have less access to informal mentoring opportunities, as they have less colleagues/networks to request this from.

Various writers have also argued women in the police may mask their femininity or behave in masculine ways to deflect unwelcome attention, blend into the system and to achieve success (Martin, 1996; Maddock, 1999; Westmarland, 2001; Silvestri, 2003). In other words, police women wanted to become one of the boys (Heidensohn, 1995). But more recently, there has become a new type of police woman who is more independent, more confident, openly feminine, more challenging, unwilling to blend in, unwilling to hold themselves back and who may be more capable than their male colleagues. Diversity policies help to support this movement in the workplace as do Home Office/ Home Affairs reports and reports from national women's associations (for instance, the British Association for Women in Policing), which suggest the implementation of new initiatives to address the inequality in the workplace.

However, despite the obvious obstacles within the Police environment, such as stereotype threat and institution-level discrimination (Kleinlogel and Dietz, 2016), there are slowly becoming more women within leadership positions, suggesting that it is possible for women to successfully negotiate the glass labyrinth (Eagly and Carli, 2007: Hoyt, 2010). Silvestri (2003) stated that those women who have conquered the glass ceiling need to be willing to act as role models and mentors to those 
women who want to be in similar positions to them. Silvestri (2003) suggested that:

the fight for a place in policing must continue to come from women themselves (p.183).

Women mentoring other women could be a way to do thishence a clear rationale for investigating these phenomena further.

In short, mentoring has been increasingly used as a development tool by many public sector organizations in the United Kingdom (Snell, 2009; CIPD Factsheet, 2016) and this sector has been subject to huge economic, political and social pressures in relation to changes in political leadership, recessions and changes in public expectations which have led to the need for institutional change (Chynoweth, 2015). New policies and priorities have needed to be adopted within the public sector to cope with this change, which has resulted in the need for different management approaches, and different organizational structures and ways of leading and managing the increasingly diverse workforce. The UK Police force is a good example of this.

\section{Methodology}

This qualitative case study took a critical realist position (Edwards, 2006) and an interpretivist theoretical perspective in an attempt to offer explanation, clarification and demystification of learning from formal mentoring (Gray, 2014; Bryman and Bell, 2015). The case study was a Central England Police force (referred to from now on as the CEPF study). Following the Home Office Assessment of Women in the Police Service Report (2010), there was a drive from within the CEPF to develop a more inclusive workforce and to increase focus on developing and promoting women. The researcher was asked by the Learning and Development team to design, deliver and evaluate a pilot formal mentoring programme aimed at giving women in this Police force an opportunity to be trained as mentors and/or be given the opportunity to be mentored by a more senior women members of the Police. The purpose of the programme was for senior policewomen to share experiences, support and encourage other women who may aspire to progress further within the Police. The formal mentoring programme was co-ordinated internally with the Police force and all women were invited to be part of the new programme. All mentors were experienced women managers (in Police Officer or Police Staff roles), at least two ranks/positions higher than the women mentees.

This mentoring programme started with 23 trained mentors, most with two or even three mentees. There were 45 dyads in total (that is, 45 mentees). Only women were involved in this mentoring programme, therefore it was not possible to compare any experiences of men.

Following the conventions of Eisenhardt (1989) and Yin (2014), a longitudinal qualitative case study approach was chosen in order to gain insights into the phenomenon of formal mentoring, within its own longitudinal context. The idea was to document the learning journey for police women mentees and mentors over time, through semi-structured interviews and focus groups. Kram's (1988) four phases of the mentoring lifecycle were used as the points for data collection over 12 months; data collection point 1 ; at the end of the initiation phase ( 3 month point), point 2; at the end of the cultivation stage (6 month point), point 3; at the end of the separation phase ( 9 month point), and point 4 ; at the end of the redefinition phase (12 month point).

In this Police study, all mentors and mentees were invited to the interviews and the focus groups and in total, 23 mentees (51.11\% of all mentees) and 19 mentors ( $82.61 \%$ of all mentors) contributed to at least one interview and/or one focus group. Some attended more often and more regularly than others; problems with availability were due to differing shift patterns, organizational changes and location. Overall 68 interviews were held (36 mentors and 32 mentees); together with two mentor focus groups and two mentee focus groups (ranging from four to eight people per group). Each interview lasted between $45-60 \mathrm{~min}$. The focus groups lasted up to two and a half hours for each group.

Content analysis (Flick, 2009; Easterby-Smith et al., 2012) was used to disentangle the substantive statements, meanings and words. Learning outcome responses were coded against the four theoretical learning domains proposed by Wanberg et al. (2003) and used by Hezlett (2005), namely cognitive, skill-based, affective-related and social networks.

\section{Findings}

What do policewomen mentees and mentors perceive they are learning during their formal mentoring relationships? The results of this study demonstrated that both parties perceived they were learning within all four learning domains (Wanberg et al., 2003); cognitive, skill-based, affective-related learning and social networks.

The results of this are summarized into Table 1 . This table shows the respective number of responses made by both CEPF mentees and mentors during their interviews in relation to the four learning domains. As well as showing number of responses and percentage of the overall total responses by learning domain, the "no. of sources" row indicates how many mentee or mentor interviews contained these responses and the percentage response rate for each learning domain overall.

This table demonstrates that although all four domains were discussed during the interviews with both mentees and mentors, the number of sources and responses varied significantly across the four learning domains.

Mentees made 66 more responses ( $14.74 \%$ more) than mentors overall. For the mentees, learning was mentioned more regularly $(n=95)$ in the affective-related learning domain, in all but one mentee interview (96.88\%) and accounted for just over a third of the total mentee responses (36.97\%). The cognitive domain was the next most frequently mentioned learning domain and was mentioned in $100 \%$ of mentee interviews; $33.46 \%$ of the responses (again approximately a third of the responses). The number of responses relating to skill based $(n=55)$ and social networks $(n=21)$ were mentioned much less, and although were the domains of least frequent comment, they were mentioned in 78.13 and $43.75 \%$ interviews respectively.

For mentors, learning was mentioned most regularly $(n=67)$ in the affective-related learning domain too with $35.08 \%$ of the total responses made, followed closely by $30.37 \%$ (58 of 191) of the responses and $28.80 \%$ (55 of 191) relating to the skill-based and cognitive domains of learning respectively. Just 5.75\% (11 of 191) of the responses made by mentors were examples of social network learning. There were no learning domains commented on within all mentor interviews (as with mentees and cognitive learning) but the majority of mentor interviews (69\% plus) had affective-related, skill based and cognitive responses included.

As can be seen in Table 1, the mentors' responses were more evenly spread between the first three learning domains (ranging from 55-67) whereas the mentees' responses tended to focus on affective-related learning more than on the other two domains of learning (ranging from 55 to 95). The combined total number of responses made by the mentees' and mentors' suggests that most of the learning that had taken place within these dyadic formal mentoring relationships was in the affective-related domain, and the least learning was in the social networks domain. 
Table 2 | Comparison of the key themes from mentee and mentor learning outcomes in each learning domain

\begin{tabular}{|c|c|c|}
\hline $\begin{array}{l}\text { Learning } \\
\text { domains }\end{array}$ & Mentors & Mentees \\
\hline Cognitive & $\begin{array}{l}\text { - Wider org } \\
\text { - About mentees } \\
\text { - About mentoring }\end{array}$ & $\begin{array}{l}\text { - Promotional info } \\
\text { - Practical advice } \\
\text { - Wider org }\end{array}$ \\
\hline Skill-based & $\begin{array}{l}\text { - Questioning } \\
\text { - Listening } \\
\text { - Planning } \\
\text { - Support } \\
\text { - Challenge } \\
\text { - Empathy }\end{array}$ & $\begin{array}{l}\text { - Interview skills } \\
\text { - Communication } \\
\text { - Coping with stress } \\
\text { - Work-life balance } \\
\text { - Reflection }\end{array}$ \\
\hline $\begin{array}{l}\text { Affective- } \\
\text { related }\end{array}$ & $\begin{array}{l}\text { - Confidence about } \\
\text { mentoring } \\
\text { - Self-awareness } \\
\text { - Positivity }\end{array}$ & - $\frac{\text { Confidence }}{\text { - }}$ \\
\hline $\begin{array}{l}\text { Social } \\
\text { networks }\end{array}$ & $\begin{array}{l}\text { - Raised awareness of own } \\
\text { contacts }\end{array}$ & $\begin{array}{l}\text { - Signposting } \\
\text { - Making connections }\end{array}$ \\
\hline
\end{tabular}

The next table (Table 2) shows the key themes emerging from both the interviews and the focus groups.

It is interesting to see that both parties discussed gaining a wider view of the organization (although potentially this was a key expectation for the mentees only) and that the skills and social networks comments were from quite different perspectives between mentee and mentor, although there were areas of potential overlap, for instance with mentors stating questioning and listening skills and mentees mentioning communication skills. In short, the mentors comments seemed to focus more on their mentoring skills and what they bring to mentoring, whereas the mentees comments seem to focus on work or promotion related aspects of interviewing, managing stress and work-life balance. However, although the focus was different, the four learning domains were still well documented by both parties. Also, comments about feeling more confident and positive were clearly common for both parties. In fact confidence was mentioned in at least half of both the mentee and the mentor interviews.

Here are some examples of what mentees were saying about their learning. They mentioned gaining a wider knowledge of the organization through the mentor's experience (cognitive):

Main issues we have discussed are around how I can get more development within my current role ...A big benefit is learning from my mentors experience and how she has progressed in her own career. Through her experience, she has had some interesting ideas which I had not thought of myself (Mentee/Interview 2).

You feel quite isolated I think, sometimes we can feel very alone in such a big organization and mentoring helps you discover that you're not (Mentee/Focus group 2).

Getting help with interview preparation (skills-based):

I'm still applying for jobs and my mentor helped me with the preparation...when it did come to the day I would dither, I 
wouldn't be able to put sentences together, which really came across and she really helped me with that (Mentee/Interview 4)

Getting help with building confidence and feeling more empowered (affective-related):

So she is really trying to push me for it. But that's good; I said I wanted someone to be behind me...you can really doubt yourself sometimes and I have been lately... a lot of the time she has just been reassuring me-saying 'you can do it, you just need to believe in yourself a lot...I've grown in confidence, definitely. I'm more likely to go for something or speak up more now than I did (Mentee/Interview 1).

And I think for women, a lot about going for promotion, or going for a specialism, is about confidence. I think mentoring helps significantly in that area. You've got an unconditional supporter that doesn't judge you, isn't involved in policing your day job, doesn't have any of those hang-ups about you doing other stuff outside of your day job...mentoring has given me more confidence to assert where I'm coming from with things... Women generally suffer from a lack of confidence, you know, "I can't do any of that, I can't do those 3 skills", whereas a bloke will go "I've got those 3 skills, I can do that" (Mentee/Interview 4).

I think it made me realize how strong I am personally and what skills I've got. Because at the beginning I was like, oh yes, I need someone to kick me up the butt and make me realize what potential I've got...I think sometimes that's not recognized in your office is it? (Mentee/Focus group 1).

I've learnt to sort of believe in yourself, because if you don't, you're not going to get anywhere...she was able to advise me and instil that confidence in me. So I think without her being there, I don't know whether I'd be here now (Mentee/Focus Group 2).

And getting help with building networks (social networks):

She's given me the link for the Women In Policing and how to get involved-sort of in terms of networking and helping out...So she's sort of guiding me in the sense (Menteel Interview 1).

Here are some examples of what mentors were saying about their learning. They mentioned gaining a wider knowledge of the organization (cognitive):

My department is quite a positive, pro-active department and it has given me an insight into other working practices with other departments, which perhaps haven't got the positivity and the support (Mentor/Interview 3).

Developing their thinking and empathy skills (skill-based):

I'm thinking in a different way. It's challenging to think from a different perspective (Mentor/Focus Group 1).

I think probably trying to display more empathy and perhaps more feeling, because I do tend to have a very professional head on a lot of the time, so ... Sometimes just sitting back and maybe giving a little bit more of myself (Mentor/Interview 4).

Building their self-awareness, their confidence and feeling more empowered (affective-related):
So it's not being arrogant, it's not being complacent, but actually, sometimes it's about that learning that I know more perhaps than I think I do sometimes... a little bit about trying to then become a bit more self-valuing than you are and increasing my confidence again (Mentor/Interview 4).

Made me listen, reflect, be grateful for who I am and where I am (Mentor/Focus Group 1).

And recognizing they know others who can help (social networks):

It amazes me how much ... or how many people I know...I said "I know so-and-so, I'll ring them up or you ring this person and they'll be able to tell you." And I suppose what it's brought home to me is actually the amount of enduring contacts I have... Even if they've moved to other roles and I've moved to other roles, I can still contact them and find stuff out (Mentor/Interview 3).

In summary, it was clear that both parties perceived they were learning a huge amount in all four learning domains but that the majority of learning was within the affective-related domain, particularly in relation to raising their self-awareness about what they can do, building their self-confidence, their positivity and ultimately feeling more empowered.

How do the comments on learning change over time for both parties? The next table (Table 3) shows how the amount of comments from both parties about their learning changed over time. A comment is made after each set of percentages stating whether the response rate has fluctuated, increased and/or decreased over time, with the second comment making it clear whether the responses have been decreasing, increasing or remained the same between the first and the final phase.

This table confirms that similarly to mentees, mentors affective-related responses increased over time and cognitive responses reduced over time. Skill-based learning seemed to follow an increasing pattern for mentors but remained the same from phase 1 to phase 4 for mentees. The trend for social network responses were different for both parties but numbers of responses remained low throughout (see Table 1 for total responses).

It seems clear from Table 3 that learning was greatest at both the start and the end phases of the mentoring relationship, for both parties. Cognitive learning was perceived to be greater at the start of mentoring and affective-related learning more likely to be discussed at the end, for both parties. Skill-based learning was more likely to be discussed at both the beginning and the end for mentees and the middle to final phases for mentors.

Mentees and mentors were also asked in their two focus group sessions what they had felt had changed within their mentoring relationships over time and the majority of comments were connected to the affective-related domain. Here are some quotes to illustrate these themes:

Rapport is getting better...I feel more at ease now (Mentee/ Focus group 1).

It has given me the clarity and confidence to put things in perspective (Mentee/Focus group 2).

The relationship is more equal now. Now we are two women who work in the same place. She asks me about me too. It's a more personal relationship (Mentor/Focus group 2). 
Table 3 | Comparison of mentee and mentor responses on the four learning domains against Kram's (1988) four phases of the mentoring cycle

Learning domains

Cognitive

Skill-based

Affective-related

Social networks
Mentors (interviews)

40\%-18\%-14\%-27\% Fluctuated/Decreasing

19\%-28\%-21\%-33\% Fluctuated/Increasing

30\%-19\%-16\%-34\% Fluctuated/Increasing

0\%-18\%-18\%-64\% Increased/Increasing
Mentees (interviews)

36\%-22\%-10\%-31\% Fluctuated/Decreasing

36\%-11\%-16\%-36\% Fluctuated/Same

26\%-13\%-21\%-40\% Fluctuated/Increasing

52\%-29\%-0\%-19\% Fluctuated/Decreasing
My mentee has become a friend. I care about her (Mentor/ Focus group 1).

There were developing themes for both parties too including feeling more comfortable, developing trust and friendship and growing in confidence.

What difference do they perceive their learning, from mentoring, makes within the workplace? Both mentees and mentors were asked over time what learning from their mentoring experiences, did they feel they had taken back into the workplace. Here are some mentee quotes to illustrate both skill-based and social network learning:

I probably take more of an active role in meetings now (Mentee/Focus group 1).

I'm now making better links with other departments (Mentee/ Interview 4).

I'm considering bringing in a buddying/mentoring scheme into my own department (Mentee/Interview 3).

\section{And affective-related learning:}

It's being aware of first impressions and what you have in your head and how you create an impression and how everyone else perceives it. You don't get many chances to make a second first impression...I think once you learn how you present yourself has an impact on you and also has an impact on your team-you can set the mood, you can set the tone back at work. (Mentee/Focus group 2).

I feel more confident in my ability to do my job (Mentee/ Interview 4).

Here are some mentor quotes to illustrate skill-based and social network learning:

I am a better communicator as well as listener now. I find it easier to problem solve. (Mentor/Focus group 2).

I have referred others I work with, to look for mentors now too. (Mentor/Interview 4)

\section{And affective-related learning:}

I'm standing up for myself more. I'm being more forceful in the workplace. (Mentor/Interview 3)

I have more confidence to approach others and offer help. (Mentor/Interview 4)
I have found it a very liberating process, you know, and it's doing the things that have been more difficult that have been the bits I've learned most from for myself and my job, and they've been the most rewarding part really. (Mentor/Interview 3)

It is interesting to see that the affective-related learning again was mostly discussed again by both parties, in terms of greater self-awareness and confidence to do more within the workplace and that both parties were considering offering mentoring to others; a sign that they can see the benefits and are keen to share them with others.

\section{Discussion}

The purpose of this research was to increase our understanding of the value of formal mentoring and specifically how mentoring can support women within the UK Police context.

The value of mentoring? The results of this study demonstrate that both parties perceived they were learning in all four domains; cognitive (for example, wider knowledge of differing perspectives in the workplace), skill-based (for example, skills to enhance work-life balance), affective-related learning (for example, increase in self-confidence) and social networks (for example, signposting to key contacts) over time. This supports the notion that formal mentoring adds value to both parties involved and supports learning and development to happen (Parsloe and Wray, 2004; Garvey, 2014). This is a useful observation, as it reinforces existing knowledge that mentoring is an important learning and development intervention and helps to set mentoring apart from other interventions which do not necessarily create a two-way process for learning, for instance within a more teacher to learner one-way relationship, within training. There are still only a few studies which have investigated the learning and benefits for both parties, at the same time; it is known through the literature that mentees benefit but not how much mentors can benefit too. Therefore, this study has added to academic thinking by reinforcing the idea that mentoring is a process of mutual growth (Megginson et al., 2006). This is an important finding as it allows practitioners to be clearer about who and what can be gained from mentoring and so can be targeted better towards individuals and particular groups.

It seems clear from these findings that mentoring develops confidence. Wenger (1999) argues that learning is not just about acquiring new knowledge and information but is about "becoming" and forming an identity for ourselves. Eraut (2004) states that confidence has an overwhelming impact on workplace learning, so it makes sense to assume that as mentees and mentors were developing their confidence through mentoring, they were also enhancing their workplace learning in other areas too. As such, this finding has highlighted the distinction between mentoring and other formal learning and development interventions offered (such as traditional structured training sessions). 
Traditionally on-the-job coaching and training are generally directed at increasing knowledge and skill levels in the workplace, whereas this research demonstrates that mentoring goes beyond these learning domains and into the more personal affectiverelated domain. This is an important addition to the literature as it is a reminder to organizations, that if they wish to develop learning from within the individual (Rogers, 1969), then mentoring could be an appropriate tool, especially as there seems to be a direct link between self-confidence and improved ability/ motivation to do the job well.

How mentoring can support women within the UK Police context? Bearing in mind that this mentoring programme was aimed at women supporting the development of other women and that an often touted factor that restricts women in the workplace is their self-confidence (related to the sticky floor syndrome), these findings help to reinforce our knowledge of the emotional bond and rewards that can be gained through mentoring (Hunt and Weintraub, 2002; Garvey, 2014), which may not necessarily be gained from other learning and development practices, for this particular group.

Although some learning domains were discussed more at different phases of the mentoring relationship, the affectiverelated learning domain was the most mentioned throughout and increased throughout. This finding advances existing academic thinking not only about the value of mentoring but about the value of mentoring for women. These results suggest that once these women mentees and mentors felt more comfortable with each other, they developed higher levels of trust in the relationship, and as such the stronger and more intimate the relationship became. As the mentoring relationship became deeper and more personal for the women involved, learning was opened up beyond the cognitive and skill-based levels. This adds to our existing thinking, as again shows that mentoring can offer women so much more in the longer term than a training programme could provide them in the shorter term. Interestingly, two subsequent studies (mentioned later) showed a similar pattern for men only and mixed gender dyads too, but there is recognition that these results are particularly interesting to women who perhaps do not have opportunities to develop supportive relationships in other ways, within the Police context.

Figure 1 helps to document the parallel journey that mentees and mentors take together (Zachary, 2012) through the mentoring phases.

Figure 1 therefore confirms the deeper, longer term learning that can be expected to be gained by both parties within formal mentoring; the "slow-burn" of mentoring, which produces the deeper, more intense personal (affective-related) learning. Interestingly, the least amount of learning reported by both parties was within social networks. This could suggest that these women mentors did not have ready access to or have less developed senior level relationships and networks to share within the workplace. Here is a quote reiterating this from one of the mentees:

So for me, and I think that's probably why I've struggled, I haven't got friends in high places and all the people I know who've got mentors they generally do tend to be men. They generally do tend to play golf with people who are substantially higher in rank ... they share shoes. Or they're on the Accelerated Promotion Scheme together (Mentee 12/ Interview 1).

This suggests that compared to their male counterparts, women may have fewer formal and informal opportunities for

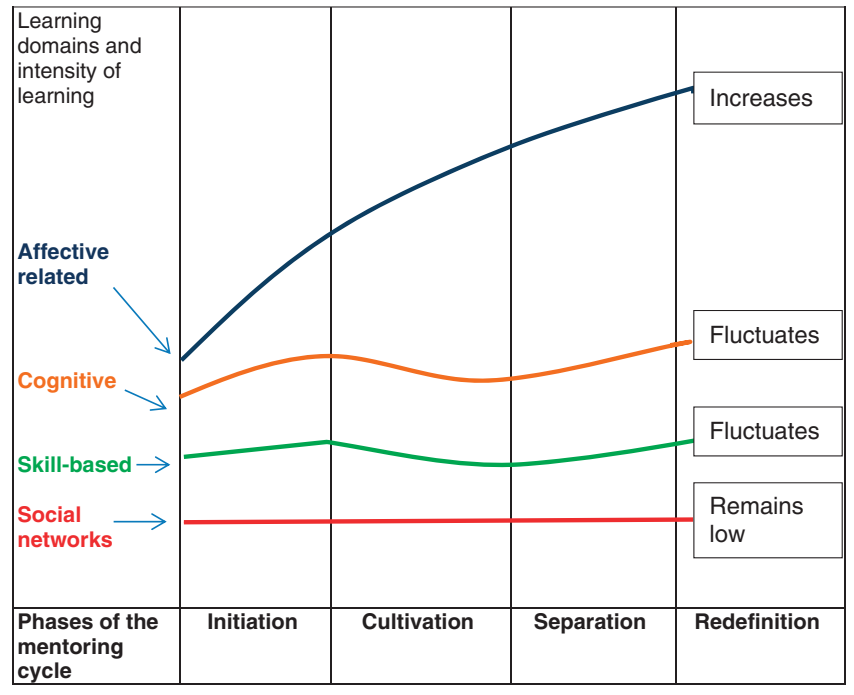

Figure 1 | A model showing the changing emphasis for the four learning domains over time, for both mentees and mentors

developing mentoring relationships (Ragins, 1996), but the results from this research suggest that if women did have access to these higher level networks through mentoring, together with an increased self-confidence within the workplace, this would put them in a much better, more equal position for career progression. Perhaps this is an area that could be achieved through other learning and development interventions and/or could be targeted by using male mentors too, who may have access to a wider, more senior network.

Finally, the findings add to our existing knowledge by potentially showing that the learning gained from mentoring makes a difference to how these women mentees and mentors felt about themselves in their workplace and therefore, the expectation is that this would a difference to their actions in the workplace too. These findings suggest that when women are supported to feel more confident and empowered within the workplace, they will promote themselves more positively within their jobs and within their teams too, which will enhance their profile within their job role. Back to previous suggestions about the "sticky floor" and potentially women holding themselves back, their learning from mentoring is an opportunity for women to push themselves forward in the workplace in a more confident, positive way.

Although this research was carried out within a women's only mentoring programme, two subsequent studies have been carried out using the same semi-structured interviews and focus group templates with another Police force mentoring programme and also within the NHS, over the same four mentoring phases (Kram, 1988). The results have been similar; mentors and mentees have learnt in all four learning domains, affective-related learning has increased over time and social network comments were least discussed. Interestingly, both these additional case studies have been with mixed dyads (men and women) demonstrating that mentoring can add value to both genders. This shows that these results are not particular to women only but perhaps are more important to women as there is a suggestion that more support is needed to enable them to progress in such a male-dominated workforce.

\section{Conclusions, implications, limitations and future research}

This article aimed to investigate the value of formal mentoring and specifically how mentoring can support women within the UK Police context. It is clear that this formal mentoring 
programme has helped to increase personal learning for both women mentees and mentors, beyond the usual training expectations of cognitive and skill-based learning (Rylatt, 2001) and has made a difference for them back into the workplace. This research has also added to our existing thinking about mentoring by showing the huge emphasis that it has in relation to affectiverelated learning for both parties, in particularly a focus on improving self-confidence and how this increases over time.

These results provide important new insights into women in the workplace, specifically women in Policing. If it is lack of knowledge of opportunities available that hinders women's progression in the workplace, then mentoring is a tool that can provide these wider organizational insights. If it is lack of interview skills, then mentoring can help develop these. If it is confidence that affects their ability to recognize their own potential to progress through the organization, then this study has shown how mentoring can provide a huge amount of support to develop self-confidence, self-awareness and positivity: all key ingredients for career success. What is also clear from this mentoring research is that both parties benefit, so whilst women mentors are role modelling behaviour and helping like-minded women (Silvestri, 2003), they are also helping themselves, which in turn will enhance both parties' prospects for further workplace success. Not to mention the obvious benefits to the workplace!

This research shows the positive impact that mentoring has on women's learning in the police service, not just within the mentoring relationship but beyond. Practically, having an improved understanding of what exactly mentees and mentors may expect to learn and how this ultimately impacts their job, helps to demonstrate the important contribution that mentoring can have to women in the workplace (Allen et al., 2006). The CIPD surveys tell us, year on year, that mentoring is increasing in popularity, but now we can share reasons why this may be so. This study shows that mentoring can have an impact across all four learning domains for all those involved, which helps makes clear the two way benefits of mentoring. This information should help to influence Learning and Development practitioners towards finding the best ways to target it, make the most of it and promote formal mentoring as a tool for supporting the development of women and other groups within the workplace. If increased self-aware, confident and empowered employees are an outcome needed within the workplace and these are typically referred to as an aspects that hold women's progression back, then mentoring is clearly a learning and development tool, which could help towards enhancing this and providing a more equal workplace.

However, mentoring is not necessarily the answer to all women's workplace challenges, as a blended approach (Jennings, 2008) may be a better approach depending on outcomes expected. If a short term acquisition of skills is needed (for instance, interviewing skills), the suggestion is that mentoring is not the intervention to most easily achieve this (perhaps a short on-the-job coaching or training session would better meet this need). If a combination of learning domains needs to be achieved and there is time to develop the "slow burn" of mentoring, then formal mentoring may well be the better choice. This is helpful information for women thinking of participating in a mentoring programme too, so that they have a better idea of what they can expect, over time.

However, again mentoring may not be the answer to all women's workplace challenges, as although this helps to target aspects of the "sticky floor", this does not necessarily target aspects of the organizational "concrete floor". Although studies have shown that senior women do refer to mentoring as one of the strategies used to break through the glass ceiling (Clutterbuck and Ragins, 2002), it is clearly not the only one, yet it is one that they could have some autonomy over. If it is agreed that mentoring can benefit women as much as men (O’Neill, 2002) and there is recognition that women do not have the same access as men may do to opportunities and networks at senior levels, then this suggests that mentoring may be more necessary for women, particularly in a male-dominated workplace. Mentoring is not the only answer but it's a start.

Therefore in short, this study makes a clear contribution as it has shown the learning benefits police women can gain from other police women whilst being involved in formal mentoring, and the suggestion is that this learning may help to put women in a better position for future progression, in such a male dominated workforce. Noe (1988) suggested that lack of mentoring for women in the workplace may have adverse effects on their job performance, their intellectual functioning and their self-efficacy, which in turn would not help to reduce gender stereotypes in the workplace. The suggestion is that exposure to successful women may help to overcome these deeper routed gender stereotypes in the workplace. All of this is important information for the Home Office, if it wishes to affect change in the gender balance within the UK Police.

Perhaps women are not the only "unsung heroes" in the workplace?

Mentoring perhaps is an 'unsung hero' in the field of development. Its potential is huge, and with careful planning and a lot of support, can be impressively effective. Innovative mentoring programmes, properly resourced and supported, should be on every HR and Organizational Development teams' agenda. (Western, 2012, p. 53)

Several limitations to this study should be recognized. Much information has been gathered from 68 interviews and four focus groups. This gives confidence in the results that the information collected represents the perceptions of this particular mentoring population; mentees and mentors. It is hoped that these results will inform wider evidence-based practice but it is recognized that this study may not be directly applicable to other mentoring programmes beyond this scheme or this Police force, due to the influence of the particular male-dominated culture in which it is located.

Alternative methods could have been used for gathering the information, for instance observations (although not always applicable in such a confidential, sensitive settings), a review of personal development plans and mentoring diaries to help avoid issues with common method bias and potentially there has been a recognition and reporting delay by respondents (Chao, 1997). Also, information was not collected from those that did not attend the interviews or the focus groups, although some phonecalls were made and emails were sent. Assumptions could be made that these mentees/mentors were having successful mentoring relationships and so did not see the value of attending and/or did not have the time available or that their mentor relationships were not as productive, so did not attend as they felt they had nothing to share and/or their mentoring had been disbanded. This information would have been helpful to pursue, to have a better understanding of those specific hindering factors which could lead to less effective or termination of relationships. Finally, it may have been difficult for both parties to distinguish between the learning and support from mentoring and other experiences within the workplace. It is very likely that some of the learning discussed and attributed to mentoring, had been developed outside of the mentoring relationship, but perhaps only realised as part of the mentoring discussions.

Therefore, ideas for future research include further testing of this model (Fig. 1) with other Police forces and/or other 
organizations to confirm the reliability and validity of results, both within women only programmes and mixed gender schemes. It would also be interesting to pursue the less positive mentoring relationships further to see what they were not learning and to uncover more detail in relation to the low levels of social network learning too. Finally, further research into the connection between trust and the intensity of learning would give further detail to expand the model and our understanding of the links within the affective-related learning domain.

\section{References}

Allen G and Dempsey N (2016) Police Service Strength Briefing Paper No. 00634 House of Commons Library, http://researchbriefings.files.parliament.uk/docu ments/SN00634/SN00634.pdf, accessed 31 October 2016.

Allen TD, Eby LT and Lentz E (2006) Mentorship behaviors and mentorship quality associated with formal mentoring programs: Closing the gap between research and practice. Journal of Applied Psychology; 91 (3): 567-578.

Aremu AO and Adeyoju CA (2003) Job commitment, job satisfaction and gender as predictors of mentoring in the Nigeria Police. Policing: An International Journal of Police Strategies \& Management; 26 (3): 377-385.

Arter M (2006) Police mentoring-Moving toward police legitimacy. Criminal Justice Studies; 19 (1): 85-97.

Baranik LE, Roling EA and Eby LT (2010) Why does mentoring work? The role of perceived organizational support. Journal of Vocational Behavior; 76, 366-373.

Barrett D (2015) Police 'must go further' on women officer numbers, says Theresa May The Telegraph, http://www.telegraph.co.uk/news/uknews/law-and-order/ 12027543/Police-must-go-further-on-women-officer-numbers-says-TheresaMay.html.

Baugh SG, Fagenson-Eland EA (2007) Formal mentoring programs In: Ragins BR and Kram K (eds). The Handbook of Mentoring at Work: Theory, Research and Practice. Sage: London.

British Association for Women in Policing. (2014) Gender Agenda 3, http://www. bawp.org/Resources/Documents/BAWP\%20Gender\%20Agenda\%203\%20final $\% 20 \% 2016$-oct-2014.pdf.

Bryman A and Bell E (2015) Business research methods, 4th edn. Oxford University Press: Oxford.

Carson D (2009) Mentoring for women in policing in the UK. International Iournal of Evidence Based Coaching and Mentoring; (Special Issue 3): 51-63.

Chandler DE and Ellis R (2011) Diversity and mentoring in the workplace: A conversation with belle rose ragins. Mentoring and Tutoring: Partnership in Learning; 19 (4): 483-500.

Chaney MA (2015) Guidance from a Mentor Helps Avoid the Pitfalls of Many New Police Chiefs The Police Chief, http://www.policechiefmagazine.org/magazine/ index.cfm? fuseaction $=$ display_arch\&article_id $=1371$ \&issue_id $=12008$, accessed 1 February 2016.

Chao GT (1997) Mentoring phases and outcomes. Journal of Vocational Behavior; 51 (1): $15-28$.

Chun JU, Sosik JJ and Yun NY (2012) A longitudinal study of mentor and protégé outcomes in formal mentoring relationships. Journal of Organizational Behavior; 33 (8): 1071-1094.

Chynoweth C (2015) The public sector faces terrifying challenges, http://www.cipd. co.uk/pm/peoplemanagement/b/weblog/archive/2015/09/23/the-public-sectorfaces-terrifying-challenges.aspx, accessed 13 December 2016.

CIPD. (2005-2015) Learning and Development and Learning and Talent Surveys 2005-2015, https://www.cipd.co.uk/knowledge/strategy/development/surveys, accessed 13 December 2016.

CIPD Factsheet. (2016) Human Capital, https://www.cipd.co.uk/knowledge/ strategy/analytics/human-capital-factsheet, accessed 13 December 2016.

Clutterbuck D and Ragins BR (2002) Mentoring and Diversity: An International Perspective. Butterworth-Heinemann: Oxford.

Derks B, Ellemers N (2016) Gender and social hierarchies: Introduction and overview In: Faniko K, Lorenzi-Cioldi F, Sarrasin O and Mayor E (eds). Gender and Social Hierarchies. Routledge: London, pp 1-7.

Devos A (2007) Mentoring and the new curriculum of academic work. Journal of Organisational Transformation and Social Change; 4 (3): 225-236.

Eagly AH and Carli LL (2007) Through the Labyrinth: The Truth about how Women Become Leaders. Harvard Business School Press: Boston, MA.

Easterby-Smith M, Thorpe R and Jackson PR (2012) Management Research, 4th edn. Sage: London.

Eby LT and Lockwood A (2005) Proteges' and mentors' reactions to participating in formal mentoring programs: A qualitative investigation. Journal of Vocational Behavior; 67 (3): 441-458.

Edwards P (2006) Industrial Relations and Critical Realism: IR's Tacit Contribution Warwick Papers in Industrial Relations 80: 1-20, https://www2.warwick.ac.uk/ fac/soc/wbs/research/irru/wpir/wpir_80_pe.pdf.
Egan TM and Song Z (2008) Are facilitated mentoring programs beneficial? A randomized experimental field study. Journal of Vocational Behavior; 72 (3): 351-362.

Eisenhardt KM (1989) Building theories from case study research. Academy of Management Review; 14 (4): 532-550.

Eraut M (2004) Informal learning in the workplace. Studies in Continuing Education; 26 (2): 247-273.

Flick U (2009) An Introduction to Qualitative Research, 4th edn. Sage: London.

Flynn M (2010) Mandatory retirement in the police service-The case of the London MPS. Policing: An International Journal of Police Strategies and Management; 33 (2): 376-391.

Garvey B (2014) Mentoring in a coaching world In: Cox E, Bachkirova T and Clutterbuck D (eds). The Complete Handbook of Coaching. Sage: London, pp 361-374.

Gianettoni L, Guilley E (2016) Sexism and the gendering of professional aspirations In: Faniko K, Lorenzi-Cioldi F, Sarrasin O and Mayor E (eds). Gender and Social Hierarchies. Routledge: London, pp 11-25.

Gibson SK (2004) Mentoring in business and industry: The need for phenomenological perspective. Mentoring and Tutoring; 12 (2): 259-275.

Gray DE (2014) Doing Research in the Real World, 3rd ed. Sage: London.

Hamlin RG and Sage L (2011) Behavioural criteria of mentoring effectiveness: An empirical study of mentor and mentee behaviour within formal mentoring relationships. Journal of European Industrial Training; 38 (8/9): 752-778.

Hansford B, Tennent L and Ehrich LC (2002) Business mentoring: Help or hindrance? Mentoring and Tutoring: Partnership in Learning; 10 (2): 101-115.

Heidensohn F (1995) Women in Control? The Role of Women in Law Enforcement. Clarendon Press: Oxford.

Hezlett SA (2005) Protégés learning in mentoring relationships: A review of the literature and an exploratory case study. Advances in Developing Human Resources; 7 (4): 505-526.

Home Affairs Committee. (2016) Police Diversity: Government Response to the Committee's First Report of Session 2016-17 House of Commons, http://www. publications.parliament.uk/pa/cm201617/cmselect/cmhaff/612/612.pdf.

Home Office. (2010) Assessment of Women in the Police Service. Home Office: London.

Hoyt CL (2010) Women and leadership In: Northouse PG (ed). Leadership: Theory and Practice; Thousand Oaks, CASAGE, pp 301-333.

Hunt JM and Weintraub JR (2002) The Coaching Manager-Developing Top Talent in Business. Sage: Thousand Oaks, CA.

Hyde JS (2014) Gender similarities and differences. Annual Review of Psychology; 65, 373-398.

ITV Report. (2015) Theresa May condemns lack of women and ethnic minorities in police forces 22/10/15, http://www.itv.com/news/2015-10-22/theresa-may-con demns-lack-of-women-and-ethnic-minorities-in-police-forces/.

Janasz de S, Behson SJ, Jonsen K and Lankau Ml (2013) Dual sources of support for dual roles: How mentoring and work-family culture influence work-family conflict and job attitudes. The International Journal of Human Resource Management; 24 (7): 1435-1453.

Jennings C (2008) The Point-of-Need: Where Effective Learning Really Matters. Saffron Interactive Advance, NC: London.

Jones J (2012) An analysis of learning outcomes within formal mentoring relationships. The International Journal of Evidence Based Coaching and Mentoring; 10 (1): 57-73.

Kirton G and Greene A-M (2010) The Dynamics of Managing Diversity - A critical approach. Butterworth-Heinemann: Oxford.

Kleinlogel EP, Dietz J (2016) A model of gender prejudice, power, and discrimination: How hierarchy-enhancing factors predominate over hierarchy-attenuating factors In: Faniko K, Lorenzi-Cioldi F, Sarrasin O and Mayor E (eds). Gender and Social Hierarchies. Routledge: London, pp 135-147. Konrad AM (2006) Cases in Gender and Diversity in Organizations. Sage: London.

Kram KE (1988) Mentoring at work: Developmental relationships in organizational life. University Press of America: London.

Laiho M and Brandt T (2012) Views of HR specialists on formal mentoringCurrent situation and prospects for the future. Career Development International; 17 (5): 435-457.

Maddock S (1999) Challenging Women-Gender, Culture and Organization. Sage: London.

Martin PY (1996) Gendering and evaluating dynamics-Men, masculinities, and managements In: Collinson DL and Hearn J (eds). Men as Managers, Managers as Men-Critical Perspectives on Men, Masculinities and Managements. Sage: London, pp 186-209.

Megginson D, Clutterbuck D, Garvey B, Stokes P and Garrett-Harris R (2006) Mentoring in Action, 2nd edn. Kogan Page: London.

Noe RA (1988) Women and mentoring. A review and research agenda Academy of Management Review; 13 (1): 65-78.

O'Neill RM (2002) Gender and race in mentoring relationships: A review of the literature In: Clutterbuck D and Ragins BR (eds). Diversity and Mentoring: An International Perspective. Butterworth-Heinemann: Oxford, pp 1-22. 
Office for National Statistics. (2015) Participation rates in the UK Labour Market2014, http://www.ons.gov.uk/ons/rel/lmac/participation-rates-in-the-uk-labourmarket/2014/index.html.

Parise MR and Forret ML (2008) Formal mentoring programs: The relationship of program design and support to mentors' perceptions of benefits and costs. Journal of Vocational Behavior; 72 (2): 225-240.

Parsloe E and Wray M (2004) Coaching and Mentoring-Practical Methods for Improving Learning. Kogan Page: London.

Perrons D (2003) The new economy and the work-Life balance: Conceptual explorations and a case study of new media. Gender, Work and Organization; 10 (1): 65-93.

Philip K and Hendry LB (2000) Making sense of mentoring or mentoring making sense? Reflections on the mentoring process by adult mentors with young people. Journal of Community \& Applied Social Psychology; 10 (3): 211-223.

Phinney JS, Torres Campos CM, Padilla Kallemeyn DM and Kim C (2011) Processes and outcomes of a mentoring program for latino college freshmen. Journal of Social Issues; 67 (3): 599-621.

Ragins BR (1996) Jumping the hurdles: Barriers to mentoring for women in organizations. Leadership \& Organization Development Journal; 17 (3): 37-41.

Ragins BR and Kram KE (eds) (2007) The Handbook of Mentoring at WorkTheory, Research and Practice. Sage: London.

Reiner R (2012) The Politics of the Police, 4th edn. OUP: Oxford.

Richards W (2001) Evaluating equal opportunities initiatives-The case for a 'transformative' agenda In: Noon M and Ogbonna E (eds). Equality, Diversity and Disadvantage in Employment. Palgrave Macmillan: Hampshire, UK, pp 15-31.

Rogers CR (1969) Freedom to Learn. Merrill: Columbus, OH.

Rylatt A (2001) Learning Unlimited-Transforming Learning in the Workplace, 2nd edn. Kogan Page: London.

Shambaugh R (2007) It's Not a Glass Ceiling, It's a Sticky Floor-Free Yourself From the Hidden Behaviors Sabotaging Your Career Success. McGraw-Hill: New York.

Silvestri M (2003) Women in Charge: Policing, Gender and Leadership. Willan Publishers: United Kingdom.

Snell P (2009) Mentors can deliver real public sector gains The Guardian https:// www.theguardian.com/society/2009/dec/02/mentors-public-sector-leaders.

Snoeren M M W C, Raaijmakers R, Niessen TJH and Abma TA (2016) Mentoring with(in) care: A co-constructed auto-ethnography of mutual learning. Journal of Organizational Behavior; 37 (1): 3-22.

St-Jean E and Audet J (2012) The role of mentoring in the learning development of the novice entrepreneur. International Entrepreneurship \& Management; 8 (1): 119-140.

Thurston PW, D'Abate CP and Eddy ER (2012) Mentoring as an HRD approach: Effects on employee attitudes and contributions independent of core selfevaluation. Human Resource Development Quarterly; 23 (2): 139-165.
Tyler MA and McKenzie WE (2011) Mentoring first year police constables: Police mentors' perspectives. Journal of Workplace Learning; 23 (8): 518-530.

Vouillot F (2007) Orientation in a gender perspective. Work, Gender and Societies; 18, 87-108.

Waddington PAJ (2006) Police (canteen) sub-culture: An appreciation In: Newburn T (ed). Policing-Key Readings Devon: Willan Publishing; pp 364-385.

Wanberg CR, Welsh ET, Hezlett SA (2003) Mentoring research: A review and dynamic process model In: Martocchio J and Ferris J (eds). Research in Personnel and Human Resource Management. Elsevier Science: Oxford, pp 39-124.

Wang Y-H, Hu C, Hurst CS and Yang C-C (2014) Antecedents and outcomes of career plateaus: The roles of mentoring others and proactive personality. Journal of Vocational Behavior; 85 (3): 319-328.

Wenger E (1999) Communities of Practice-Learning, Meaning, and Identity. Cambridge University Press: Cambridge.

Western S (2012) Coaching and Mentoring-A Critical Text. Sage: London.

Westmarland L (2001) Gender and Policing-Sex, Power and Police Culture. Willan Publishing: Devon, UK.

Yin RK (2014) Case Study Research: Design and Methods, 5th edn. Sage: London Zachary LJ (2012) The Mentor's Guide-Facilitating Effective Learning Relationships, 2nd edn. Jossey-Bass: San Francisco, CA.

\section{Data availability}

The datasets generated during and/or analysed during the current study are not publicly available due to potential compromises in participant confidentiality; however, selected sections of notes taken are available from the corresponding author on reasonable request.

\section{Additional information}

Reprints and permission information is available at http://www.palgrave-journals.com/ pal/authors/rights_and_permissions.html

How to cite this article: Jones J (2017) How can mentoring support women in a maledominated workplace? A case study of the UK police force. Palgrave Communications. 3:16103 doi: 10.1057/palcomms.2016.103.

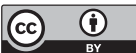

This work is licensed under a Creative Commons Attribution 4.0 International License. The images or other third party material in this article are included in the article's Creative Commons license, unless indicated otherwise in the credit line; if the material is not included under the Creative Commons license, users will need to obtain permission from the license holder to reproduce the material To view a copy of this license, visit http://creativecommons.org/licenses/by/4.0/ 